\title{
An Evaluation of Motherhood Experience in Pursuit of Postgraduate Study in Kenya
}

\author{
Lucy Wanjiku Musili ${ }^{1}$ \\ African Women Study Centre, University of Nairobi, P.O. Box 30197 - 00100, Nairobi, Kenya
}

\begin{abstract}
This research study is an evaluation of motherhood experience in pursuit of postgraduate study in Kenya. The study has three objectives: 1) Learn more about the experiences of mothers who study at postgraduate level; 2) Analyze impact of postgraduate study on women and 3) Evaluate how mothers who study resolve tension of combining motherhood and education. Using a qualitative approach, the study gathered data through open-ended interviewing questioning from 32 female participants who reported in their role as mothers of child (ren) eighteen years old or younger enrolled for postgraduate study at University of Nairobi. These study findings reveals that postgraduate student mothers experienced conflict between various commitments like childcare, domestic, work and academic duties. However, nearly all the women reported ways in which they resolved tension that affected their studies on their families by employing positive coping strategies. Participants' success appeared to be based on being organized and making sacrifices in other areas of their lives, time-management skills, family support and by sacrificing sleep and recreating time for their families. Women in this study experienced numerous benefits as a result of their study. Individual benefits included increased selfesteem and a sense of professional identity. Children also benefitted from their mother's postgraduate education because she provided a positive educational role model, developed skills to assist her children with their own education, and positioned her to improve the financial future of her family.
\end{abstract}

\subsection{Background}

\section{INTRODUCTION}

Motherhood is an idealized role that marks a significant shift in the familial lives of women and their place in society (Heisler \& Ellis, 2008). It is continuously redesigned in response to changing economic and societal factors that changes with time and place (O'Really, 2004). Most cultures have specific rules that define the role of motherhood thereby institutionalizing mothers' roles (Walls, 2007). A good mother is typified as one who remains at home and makes the primary focus of her world and the development of her children (Gorman and Fritzsche, 2002). This belief persists regardless of the increasing number of women who work outside the home. Employed mothers are still responsible for the daily care and wellbeing of children and for running the household despite working outside the home (Lynch, 2008). The socially-constructed definitions of good student and good mother stratify the identity intersectionality of graduate student mothers in today's higher education system (Lynch, 2008). Unable to separate the two identities (i.e. mother and student), some graduate student mothers default to maternal invisibility (Lynch, 2008) in order to convince their peers (Jiron-King, 2005) and advisors (Bolick, 2010) that they are serious and committed scholars. A study by Lynch (2008) found high attrition rates related to this group of graduate students who faced difficulties combining the two identities of "mother" and "student". This helps to explain why postgraduate student mothers are more likely than their male classmates to drop out before finishing their degree and take longer to complete their dissertations. In Kenya, poverty issues are the greatest impediments to access to education by women especially in situations where choices have to be made on whether to take boys or girls to school. This is due to gender-insensitive policies and public attitudes that are permissive to discontinuation of girls from school and socio-cultural orientations that inculcate gender differences in performance.

\subsection{Objectives}

a) Learn more about the experiences of mothers who study at postgraduate level;

b) Analyze impact of postgraduate study on women; and

c) Evaluate how mothers who study resolve tension of combining motherhood and education.

\section{2. METHODS}

\subsection{Introduction}

The study focused on motherhood experience in pursuit of postgraduate study in Kenya. Owing to the nature of this study, the research design was mainly qualitative and face-to-face in-depth interviews were conducted by the researcher with 32 female students reported in their role as mothers of child (ren) eighteen 
years old or younger enrolled for postgraduate study at University of Nairobi using an interview guide. In this study, qualitative research method focused on the way graduate student mothers interpret and make sense of their experiences and the world in which they live (Artikson et al., 2001). The use of qualitative research enabled the researcher to gain a rich, in-depth understanding to why these mothers return for postgraduate studies and their experiences in combining the two roles of motherhood and education. The researcher chose this design because it uses open-ended questions in the interview, where the participants provide their own answers to the subject of investigation. This allowed the meanings and experiences of postgraduate student mothers to be captured allowing more freedom to give honest and specific answers. Here the researcher maintained direct contact with participants by asking and clarifying questions as needed (Creswell, 2009). By using qualitative research, the researcher gained greater insight into the behaviour of the postgraduate student mothers and the reasons that govern such behaviors. The study was carried out at the University of Nairobi which is a collegiate research university based in Nairobi and one of the largest institutions of higher learning in Kenya. The university has six colleges namely: Agriculture and Veterinary Sciences, Architecture and engineering, Biological Sciences, Education and External Studies, Health sciences, as well as college of humanities and Social Sciences (University of Nairobi, 2013). Purposive selection of this institution ensured that diverse views of students from all disciplines were captured. University of Nairobi is a public institution with diversified academic programmes and specializations in sciences, applied sciences, technology, humanities, social sciences and the arts. It records the largest number of student admissions for degree courses per annum. It comprises both regular and parallel students who attend classes day and evening. These students come from different walks of life with different interests and skill sets. Purposive selection of this institution ensured diversity as the researcher was able to capture diverse views represented by both groups regarding role strain.

\subsection{Sampling Design of the Study}

The study adopted both probability and non-probability sampling methods. More specifically, the study adopted purposive and snowball sampling techniques. University of Nairobi was selected purposively. In selecting 32 student mothers, snowball sampling method was adopted.

\subsection{Type and Sources of Data}

In this study, both primary and secondary sources of data were used to understand the benefits of postgraduate education on women. Primary data was gathered directly from individual postgraduate student mothers (Key respondents) from university of Nairobi by use of an interview guide respectively. Observational data involved noting and recording of events and behaviors of postgraduate student mothers by use of observation checklist. In this study, the researcher employed both participant and non-participant observation. Here observational methods have the advantage of directly evaluating learners' involvement and engagement in the learning environment and with the learning activities. Secondary data was obtained from university records, organizational records semi-structured and structured interviews, field notes, observation records and other personal, research-related documents.

\subsection{Data Analysis}

The study employed qualitative procedure of data analysis. The individual responses were analyzed, categorized and interpreted to draw conclusions. First, the researcher read through the transcripts and jotted down comments, notes, thoughts, and observations in the margins. Second, the researcher summarized the marginal notes by grouping data into various themes. Third, code labels were assigned to each section. Fourth, the preliminary codes were examined for overlap and redundancy. Fifth, the researcher eliminated redundant codes and collapsed similar codes, which were narrowed down to broader themes. The new list of code words was then used to examine whether these codes revealed common themes and recurring patterns. Last, the different data sets was continuously read and analyzed to refine the categories and to ensure that no text sections was overlooked. The findings were presented in narrative and prose for form.

\subsection{Social and Demographic Characteristics}

\section{RESULTS}

The participants comprised of thirty two female postgraduate students studying at University of Nairobi. Twenty one of the participants were enrolled in a Masters program while eleven were PhD students. The women ranged in age from 25 to 58 years old, and the number of children each woman had ranged between one and four children. The participants' children were aged between 1-36 yrs. Table 3.1 provides further demographic information about the participants and their children. 


\begin{tabular}{|c|c|c|c|c|c|c|c|c|c|c|}
\hline S.N & Age & Degree & $\begin{array}{l}\text { Degree } \\
\text { Specialinatio } \\
\text { n }\end{array}$ & $\begin{array}{l}\text { Marital } \\
\text { Statw }\end{array}$ & Religion & $\begin{array}{l}\text { No. } \\
\text { of } \\
\text { Kid }\end{array}$ & $\begin{array}{l}\text { Age of } \\
\text { Chindren }\end{array}$ & Calloge & $\begin{array}{l}\text { Family } \\
\text { Support }\end{array}$ & $\begin{array}{l}\text { Additional Notes (Balancing Gender } \\
\text { Roles }\end{array}$ \\
\hline Rl & 32 & Master & Pplanning & Married & Protestant & 1 & 2 & CEES & Support & Family duties greatly affect by study \\
\hline$R 2$ & 33 & Master & Sociology & Married & Protestant & 2 & 9 and 5 & CHSS & & Time and work overload constraints \\
\hline $\mathrm{R3}$ & 47 & Master & $\mathrm{CD}$ & Married & Protestant & 2 & 18 and 10 & CHSS & No Support & Disappointments from Department \\
\hline R4 & 38 & Master & $\mathrm{CD}$ & Married & Catholic & 4 & $15,11,9,11$ & CHSS & Support & Ability to balance conflicting roles \\
\hline R5 & 34 & Master & Finance & Mamried & Catholic & 2 & 9 and 7 & CHSS & Support & Coping well with studies \\
\hline R6 & 29 & $\mathrm{PhD}$ & Finance & Married & Protestant & 1 & 4 & CHSS & Support & Challenged by Financial constraints \\
\hline R7 & 32 & $\mathrm{PhD}$ & & Married & Protestant & 2 & 8 and 3 & CHSS & & Exhaustion from conflicting tasks \\
\hline RS & 33 & & $\mathrm{HR}$ & Marg & $\operatorname{stan} t$ & 1 & 2 & CHSS & & Baby reduces my concentration \\
\hline$\frac{N O}{R g}$ & 44 & Master & P. Planning & Single & Protestant & $\frac{2}{2}$ & 15 and 17 & CEES & Support & Conflicting roles reduces study time \\
\hline R10 & 35 & Master & $\mathrm{CD}$ & Single & Protestant & 1 & 3 & CHSS & Support & Money is the problem \\
\hline Rl1 & 44 & $\mathrm{PhD}$ & Finance & Married & Cat. & 2 & 15 and 13 & CHSS & No Sopport & Insufficient reading time \\
\hline R12 & 47 & $\mathrm{PhD}$ & Nursing & Mamied & estant & 4 & $23,20,17,9$ & CHS & & Supervisor has issues with ny tribe \\
\hline R13 & 37 & & $\mathrm{CD}$ & Married & & 4 & 13 and 10 & CHSS & & Uncooperative unfriendly lectures \\
\hline R14 & 34 & Master & & & & 2 & 6 and 9 & CEES & & Unsupportive employer \\
\hline R15 & 32 & Master & $\mathrm{CD}$ & Married & Protestant & 1 & 1 & CHSS & No Srpport & discouragement from my department \\
\hline R16 & 43 & $\mathrm{PhD}$ & Bus Admin & Married & Catholic & 3 & $21,17,13$ & CHSS & Support & Ability to balance Conflicting roles \\
\hline R1? & 33 & Master & Sociology & Married & Protestant & 2 & 9 and 5 & CHSS & No Support & Goilty of squeezed family time \\
\hline R18 & 29 & Master & P. Planning & Married & Protestant & 2 & 5 and 3 & CEES & & Coping well with roles \\
\hline R19 & 32 & & & amried & ant & 1 & 7 & CHSS & Svoport & llenge \\
\hline R20 & 58 & Master & er Mnt & Married & $\tan t$ & 4 & $36,32,3118$ & CHSS & No Support & Money issues is my challenge \\
\hline R21 & 28 & Master & Joumalism & Single & Cat & 1 & 3 & CHSS & Support & Coping well with roles \\
\hline $\mathrm{R} 22$ & 35 & $\mathrm{PhD}$ & Joumalism & Single & Catholic & 1 & 12 & CHSS & Support & I grieritire werk xcheal then famly \\
\hline R23 & 38 & $\mathrm{PhD}$ & Education & Married & Protestant & 3 & 9,6 and 3 & CEES & No Sroport & Great Support by employer \\
\hline R24 & 46 & & & Married & & 2 & 13 and 9 & CEES & port & Cor \\
\hline R25 & 35 & Master & Bus Admin & Married & Protestant & 2 & 5 and 3 & CHSS & No Sroport & Demands from family roles \\
\hline R26 & 34 & Master & Architecture & Married & Protestant & 2 & 6 and 3 & $\mathrm{CAE}$ & Support & Challenges from children \\
\hline R2? & 40 & Master & Sociology & Mamied & Protestant & 4 & $16,12,8,4$ & CHSS & Support & challenge in balancing roles \\
\hline R28 & 44 & Master & Law & Married & Catholic & 2 & 13 and 8 & CHSS & Support & Unable to balance Roles \\
\hline $\mathrm{R} 29$ & 31 & $\mathrm{PhD}$ & & Single & Protestant & $\frac{-}{2}$ & 4 and 1 & CHSS & No Support & Difficulties combining roles \\
\hline $\mathrm{R30}$ & 25 & $\mathrm{PhD}$ & P. Mat & Single & Protestant & $\frac{2}{1}$ & 2 & CEES & Support & Difficulties ir \\
\hline R31 & 28 & Master & C. Change & Single & Catholic & 1 & 2 & CBPS & Support & Money issues is my challenge \\
\hline R32 & 46 & $\mathrm{PhD}$ & Finance & Married & Protestant & 3 & $16,12,8$ & CHSS & No Sypport & Golty of squeezed family time \\
\hline
\end{tabular}

Table 3.1 Showing Summary of Demographic Information on Participants and their Children

\section{Relevant Themes to Experiences of Balancing Motherhood and Postgraduate Study}

In this study, participants identified a number of issues relevant to the experiences of mothers who study at postgraduate level.

\section{Themes}

a) Experiences of mothers who study at postgraduate level

b) Impact of postgraduate study on women

c) Resolving tension of combining motherhood \& education: Positive coping strategies

\section{Sub-themes}

Balancing roles impact on finances, children and partner

\subsubsection{Experiences of Mothers who Study at Postgraduate Level}

\section{* Difficulties in Balancing Roles:}

In this study, majority of women reported that the experienced tension in their efforts to balance their multiple roles of childcare, domestic chores and school work. The challenges identified were insufficient reading time and a feeling of guilt due to sacrificed family time, burnout-exhaustion due to conflicting roles of motherhood and study. However, mothers challenged these expectations to incorporate a provider role, which is incompatible with the traditional notion of a "good mother". These finding differs with those in Pare's (2009) that did not challenge the ideology of intensive mothering but were presented in terms of "good mother".

\section{* Timetabling and Mode of Delivery:}

Women were able to organize their children around the school time table. Coordinating university timetable with school holiday was mentioned by mothers of school-aged children. University of Nairobi was mentioned for offering evening classes and part-time classes which was the major reason why women selected this institution.

\subsubsection{Impact of Postgraduate Study on Women \\ * Financial Impact}

For all the other mothers, returning to study resulted in financial sacrifice and strain on the family budget resulting to financial hardship. R10 complained of squeezed family budget by her studies that made her family suffer a big deal. This is consistent with the findings by Lynch, (2008), that revealed how lack of financial aid 
was the most common complaint made by graduate mothers.

\section{* Impact on Family Life and Children}

Impact of studying was mainly negative for many women and was severe during semester for their children. This resulted to a sense of guilt due to sacrificed family time. R30 indicated that she felt guilty due to squeezed family time since she no longer spent quality time with her young children. R1 related that family duties were greatly affected by her studies while R17 indicated that she was haunted for sacrificing family time. This is consistent with Estes' (2011) findings that, while student parents believed that their children were a priority, this changed as they tried to fulfill their responsibilities as students.

\section{* Impact on Relationship with Partner}

For some women their return to study at times put strain on their relationship, but it did not pose any long-term threat to the partnership. These findings concurs with those in a study by White, (2008), that reported that returning to education challenged womens' marriage, resulting in a near breakdown of the relationship.

\subsubsection{Resolving Tension of Combining Motherhood and Education}

Findings of this study show that although studying while raising children involves a lot of juggling; this led the researcher to consider the strategies used to do this successfully.

\section{* Organization}

Women complained of difficulty in balancing multiple role commitments while simultaneously studying and raising children. They spoke of feeling overwhelmed by the enormity of their loads. The key to balancing study with their family was being extremely organized and arranging their lives to meet all of their competing commitments. They worked to a strict routine, time management and proper scheduling, to focus on their studies and be available to their families. This relate with a research by Estes' (2011) whereby student parents used positive coping strategies.

\section{* Sacrifice}

Many women spoke of fatigue and burn out that accompanied trying to balance studying and motherhood, they sacrificed sleep, time with their family and friends, to focus on their studies. They often worked late into the night when their children were asleep, or early in the morning before they awoke. These research findings concur with Vyronides and Visilakis' (2008), where student mothers sacrificed sleep in order to study after their children had gone to bed while White's (2008), spoke of a double burden of juggling family roles with their studies.

\section{* Individual Factors:}

Participants demonstrated strength of mind that sustained them throughout their challenges. Most mentioned ambition, discipline, determination, and persistence. To all, an inner sense of determination helped them through the difficulties of studying with children.

\section{* Support System:}

Quality and quantity of this support varied, but in some cases it was this support that enabled women cope conflicting roles. Family provided the most reliable support followed by workplace where available while University failed to meet student needs. This may imply that women did not actively seek out university support because it was time consuming above their already full workloads. This finding concur with Springer et al, (2009), that discovered institutional issue in difficulties of combining motherhood with education, meaning, if universities offered mothers more support, the difficulties that they faced could be eliminated.

\section{DISCUSSION}

This study evaluates motherhood experience in pursuit of postgraduate study in Kenya. Results demonstrated that over the course of their studies women employed positive coping strategies to deal with the challenges that arose in balancing conflicting roles of motherhood and education.

\section{* Financial Concerns}

This study also reveals that financial concerns had a major impact on the women. They worried about buying the resources necessary for their studies, paying their bills as well as feeding their children. Women reconciled their financial hardships with the belief that in the long term, their education would lead to an improved career prospects and an improved finances for their family. This relates to the findings by Lynch, (2008), that revealed 
that a lack of financial aid was the most common complaint made by these women.

\section{* Educational Role Model}

Women believed that their children benefitted from the role-modeling they provided for them. For example, R4 said that she was her children's motivator by just seeing her study and her success of balancing studying with her other commitments. This is in line with findings by Suitor et al., (2008) that confirmed that women had reported being successful educational role model for their children.

\section{* Valuable Parenting Skills}

Women indicated that by participation in higher education, they gained valuable parenting skills by giving them tools for their own children. For example, R18 explained that enrolling for postgraduate study made her much more patient to the learning process of her own children". This concurs with White's (2008) findings that mothers studying believed that their assisted them to better aid their own children's education especially those in teaching courses that enable to implement that with their children. Women studying in disciplines other than education applied the skills they learned to benefit their children.

\section{* Improved Financial Future:}

This study revealed that having a mother in postgraduate study benefited children because they were able to look forward to an improved financial future. The mothers believed that obtaining a postgraduate education would give them better career prospects and therefore, improve their earning capacity. For example, R5 explained that her decision to study at postgraduate level was motivated potential earning power whereas her choice of undergraduate degree was motivated by a passion and desire for the subject area. This enabled her to putting herself in a position where she could properly care for her children.

\section{CONCLUSION}

This study was an evaluation of motherhood experiences in pursuit of postgraduate study in Kenya. Findings from this study confirms that experience of combining motherhood and postgraduate education involved challenges, motivation, sacrifice, financial hardship and impacted every aspect of a woman's life. However, women were committed to their education and believed that the challenges of combining their studies and motherhood were balanced out by providing her with tangible and intangible rewards. Results demonstrated that women were able to cope with the demands of combining motherhood with education by resolving the tension by employing "positive coping" strategies. This is contrary to findings by Lynch's (2008 that indicated that student mothers employed "negative coping" strategies.

\section{REFERENCES}

[1] Ahrens, C. and Ryff, D. 2006. Multiple Roles and Well-being: Socio-Demographic and Psychological Moderators. Published online: Springer Science and Business Media, Inc.

[2] Atkinson, P. 2001. Handbook of Ethnography. Los Angeles: Sage.

[3] Estes, K. 2011). "Managing the Student-Parent Dilemma: Mothers and Fathers in higher education". Symbolic Interaction, 34 (2): 198-219.

[4] Creswell, J.W. 2012. Educational Research: Planning, Conducting and Evaluating Quantitative and Qualitative Research $\left(4^{\text {th }}\right.$ Ed), Boston, M.A: Pearson.

[5] Gorman, K., \& Fritzsche, B. 2002. "The good-mother stereotype: Stay at home (or wish you did!)" Journal of Applied Social Psychology, 32, 2190-2201.

[6] Heisler, J. and Ellis, B. 2008. "Motherhood and the Construction of "Mommy Identity": Messages about Motherhood and Face Negotiation. Communication Quarterly, 56, 445-467.

[7] Jiron-King, S. 2005. "La Estudiante Caminante: My Mother work is here, my other work is there". 
In Bassett R. H.(Ed), Parenting and professing: Balancing family work with an academic career. (pp. 21-33). Nashville, TN: Vanderbilt University Press.

[8] Lynch, K. 2008. 'Gender Roles and the American Academe: A Case Study of Graduate Student Mothers”. Gender \& Education, 20 (6): 585-605.

[9] O'Reilly, Porter, M. and Short, P. 2005. 'Introduction' in Motherhood: Power and Oppression. Toronto: Women's Press.

[10] Pare, E.R. 2009. "Mother and student: The experience of mothering in college". (Unpublished doctoral Dissertation).Wayne State University, Detroit MI.

[11] Springer, K.W., Parker B. K., \& Leviten-Reid, C. 2009. "Making space for graduate student parents: practice and politics". Journal of Family Issues, 30, 435-457.

[12] University of Nairobi. 2013. Annual Report. Nairobi: University of Nairobi, Office of the Vice Chancellor.

[13] Vryonides, M., and Vitsilakis, C. 2008. "Widening Participation in Postgraduate Studies in Greece: Mature Working Women Attending an E-Learning Programme”. Journal of Education Policy, 23 (3): 199-208.

[14] Walkup, V. 2007. Gender Differences in Aspirations and Attainment. Cambridge: Cambridge University Press.

[15] White, S. 2008. "Mothers who are student teachers: Navigating their dual roles in pre-service teacher education". Studies in Continuing Education, 30(2), 159-172. 